\title{
Alkaline anion-exchange radiation-grafted membranes for possible electrochemical application in fuel cells.
}

\author{
Timothy N. Danks, Robert C. T. Slade* and John R Varcoe \\ Chemistry, The University of Surrey, Guildford, GU2 7XH U.K. Fax: 44 1483 686851; Tel: 44 1483 686855; \\ E-mail: r.slade@surrey.ac.uk
}

\begin{abstract}
This submission was created using the RSC Article Template (DO NOT DELETE THIS TEXT) (LINE INCLUDED FOR SPACING ONLY - DO NOT DELETE THIS TEXT)
\end{abstract}

Vinylbenzyl chloride was grafted onto PVDF and FEP polymer films using the radiation-grafting methodology. Subsequent reaction with trimethylamine and ion-exchange with potassium hydroxide yields alkaline anion-exchange membranes that are capable of conducting hydroxide ions; such membranes may be suitable for use in low temperature direct methanol fuel cells for portable devices. The PVDF based materials underwent an undesirable degradation and were found to be less suitable for this class of membrane. FEPbased materials exhibited superior structural stability, conductivities up to $0.02 \mathrm{~S} \mathrm{~cm}^{-1}$ at room temperature, and good retention of ionexchange capacities when treated in water at $60^{\circ} \mathrm{C}$.

\section{Introduction}

The relative advantages of solid polymer membrane direct methanol fuel cells (DMFCs) compared with polymer exchange membranes fuel cells (PEMFCs), fuelled directly with hydrogen or indirectly fuelled via on-board reformation, is currently a hot source of debate in the transportation sector. ${ }^{1}$ However, DMFCs producing $<500 \mathrm{~W}$ power and operating in the temperature range of $-20-50^{\circ} \mathrm{C}$ are ideally positioned and urgently required to act as a "disruptive technology" to replace batteries in portable devices (laptops, cellular phones, PDAs, human (soldier) portable power packs, digital cameras, and power tools) $;^{2}$ the driver is the ever increasing power demands ${ }^{3}$ which, in the immediate future, will surpass levels projected to be achievable with secondary battery technology (e.g. lithium ion batteries). It is increasingly believed that portable DMFCs will be the first fuel cells commercially available to the general public.DMFCs are amenable to such applications due to the good energy density ( $5-10$ times that of batteries $)^{3}$ of liquid methanol. Another benefit of using DMFCs instead of batteries is "instant" refuelling when utilising a plug-in methanol cartridge.

Two obstacles found with the use of commercially available proton-exchange membranes (PEMs) that inhibit application of DMFCs are (i) the relatively low activity and high costs of methanol electro-oxidation catalysts and (ii) parasitic methanol crossover. ${ }^{4}$ This parasitic crossover reduces the operational voltage and power that can be achieved; traditionally, to minimise crossover, the methanol is diluted in water $(1-2$ mol $\mathrm{dm}^{-3}$ ) which means a lower energy density. Inefficient catalysis was the principle reason why liquid electrolyte (hydrogenfuelled) alkaline fuel cells (AFCs) were developed to a significant level. Catalysts generally perform better in alkaline media and lower loadings and a wider range of catalyst may also be used. ${ }^{5}$

McLean et al. observed in a recent review on AFCs that there might be advantages in utilising polymer alkaline membranes. ${ }^{5 a}$ This is coupled with the recent growing interest in the literature and patents on using anion-exchange membranes (AEMs) in fuel cells; ${ }^{6}$ examples being recent work on alkali doping of poly(ethylene oxide) ${ }^{6 \mathrm{e}}$ or poly(benzimidazole $)^{6 \mathrm{f}}$ polymers. The thermal stability of a commercially available, but undisclosed, AEM with (benzyl)trimethylammonium moieties radiationgrafted onto PTFE membranes was good up to temperatures of $50-60^{\circ} \mathrm{C}$ in sodium hydroxide $\left(6 \mathrm{~mol} \mathrm{dm}{ }^{-3}\right)$ solution; ${ }^{7}$ this is a suitable maximum temperature range for the application of the above mentioned membranes in portable devices.
Under alkaline conditions the fuel cell reactions with methanol as a fuel are:

$$
\begin{aligned}
& \text { Anode: } \mathrm{CH}_{3} \mathrm{OH}+6 \mathrm{OH}^{-} \rightarrow \mathrm{CO}_{2}+5 \mathrm{H}_{2} \mathrm{O}+6 \mathrm{e}^{-} \\
& \text {Cathode: } 3 / 2 \mathrm{O}_{2}+3 \mathrm{H}_{2} \mathrm{O}+6 \mathrm{e}^{-} \rightarrow 6 \mathrm{OH}^{-} \\
& \text {Overall: } \mathrm{CH}_{3} \mathrm{OH}+3 / 2 \mathrm{O}_{2} \rightarrow \mathrm{CO}_{2}+2 \mathrm{H}_{2} \mathrm{O}
\end{aligned}
$$

Product water is formed at the anode, in contrast to a cell containing a PEM. An alkaline AEM may reduce methanol crossover from the anode to the cathode as the electro-osmotic water transport occurs in the opposite direction. The wider repertoire of catalysts means that a cathode catalyst may be available that does not oxidise methanol, so reducing the effect of methanol crossover further. If crossover can be eliminated, the use of undiluted methanol as a fuel is feasible, resulting in maximised energy density; thinner membranes with lower resistance can be used further improving performance. Polymer alkaline exchange membranes are reported to function in the presence of carbonate and hydrogen carbonate ions, which are formed from $\mathrm{CO}_{2}$ gas located in the air feed; these contaminants inherently cause problems in liquid (aqueous $\mathrm{KOH}$ ) electrolyte AFCs and are the reason why traditional AFCs are not fuelled by methanol, which produces $\mathrm{CO}_{2}$ as a reaction product (Eqn. 3). In fuel cell membrane research, the effort has concentrated on PEMs with lower methanol permeabilities ${ }^{8}$ and lower cost than Nafion ${ }^{\circledR}$ (> US\$ $\left.780 \mathrm{~m}^{-2}\right)^{9}$ (note, it has been recently reported that new solution cast Nafion ${ }^{\circledR}$ membranes (NR-111) would allow the cost to drop to US\$ $50 \mathrm{~m}^{-2}$ with volume production of $\sim 2$ million $\mathrm{m}^{2}$ per annum). ${ }^{10} \mathrm{~A}$ proportion of this effort has examined the radiation-grafting (using $\gamma$-rays and $e$-beams) of styrene onto non-fluorinated films ${ }^{11}$ such as poly(ethylene), partially fluorinated films ${ }^{11,12}$ such as poly(ethylene-cotetrafluoroethylene) (ETFE, $\left.-\left[\mathrm{CH}_{2} \mathrm{CH}_{2}\right]_{\mathrm{n}}\left[\mathrm{CF}_{2} \mathrm{CF}_{2}\right]_{\mathrm{m}^{-}}\right)$and poly(vinylidene fluoride) (PVDF, $-\left[\mathrm{CH}_{2} \mathrm{CF}_{2}\right]_{n^{-}}$), and fully fluorinated films ${ }^{13}$ such as poly(tetrafluoroethene-cohexafluoropropylene) (FEP, $\left.-\left[\mathrm{CF}_{2} \mathrm{CF}_{2}\right]_{\mathrm{n}}\left[\mathrm{CF}\left(\mathrm{CF}_{3}\right) \mathrm{CF}_{2}\right]_{\mathrm{m}^{-}}\right)$with subsequent sulfonation to yield cation-exchange sites. The attractiveness of this methodology is that the films are preformed and the properties and compositions of the final materials are highly tailorable. ${ }^{11 a, 13 a}$ Radiation-grafted PEMs of this type have already been tested in a DMFC setup by Scott $e t$ al. ${ }^{14}$

There is, however, some concern about the lack of stability of these membranes in a fuel cell environment, ${ }^{15}$ with peroxyradical attack of the $\alpha$-hydrogen of the styrenic backbone being principally responsible (especially at the anode); ESR studies, ${ }^{15}$ however, suggest that the $\mathrm{OH} \cdot$ radicals are only damaging at $\mathrm{pH}$ 
$<11.7$, and so this side reaction should be minimised in alkaline membranes.

If vinylbenzyl chloride (VBC), a versatile monomer, ${ }^{16}$ is grafted onto PVDF and FEP instead of styrene, anion- as opposed to proton-exchange membranes are produced (Scheme 1). ${ }^{17}$ This article extends on the work reported in our recent communication regarding the synthesis and characterisation of alkaline AEMs that may be applied to low temperature DMFCs and AFCs. ${ }^{18}$

\section{Experimental details}

\section{Instrumentation}

\section{Nuclear magnetic resonance}

High-resolution ${ }^{1} \mathrm{H}$, and ${ }^{13} \mathrm{C}\left\{{ }^{1} \mathrm{H}\right\}$ NMR solution spectra were collected on a Bruker DRX-500 NMR spectrometer. All samples were prepared as dilute solution in d-chloroform unless otherwise stated and with TMS as a shift reference.

High-resolution solid state ${ }^{13} \mathrm{C}\left\{{ }^{1} \mathrm{H}\right\},{ }^{15} \mathrm{~N}\left\{{ }^{1} \mathrm{H}\right\}$ and ${ }^{19} \mathrm{~F}\left\{{ }^{1} \mathrm{H}\right\}$ data were collected at the EPSRC solid state service at the University of Durham on a Varian Innova spectrometer (with a ${ }^{1} \mathrm{H}$ resonant frequency of $300 \mathrm{MHz}) .{ }^{19} \mathrm{~F}\left\{{ }^{1} \mathrm{H}\right\}$ spectra $\left(\mathrm{CFCl}_{3}\right.$ shift reference) were recorded using direct polarisation (giving quantitative results) and a magic angle spinning rate of $13-14 \mathrm{kHz} .{ }^{13} \mathrm{C}\left\{{ }^{1} \mathrm{H}\right\}$ (TMS as a shift reference) and ${ }^{15} \mathrm{~N}\left\{{ }^{1} \mathrm{H}\right\}\left(\mathrm{CH}_{3} \mathrm{NO}_{2}\right.$ as a shift reference) spectra were recorded using cross polarisation (with a flip-back pulse after acquisition) and spinning rates of 3 - $5 \mathrm{kHz}$. Measurements were carried out at ambient temperature and pressures. All solid state NMR spectra were recorded in a single batch to keep the experimental conditions consistent. To record spectra of aminated samples the samples were air dried before measurement.

\section{Vibrational spectroscopy}

Infrared spectra were collected on a Nicolet 510P FT-IR spectrometer and recorded with 32 scans with a resolution of 2 $\mathrm{cm}^{-1}$. Liquid samples were prepared as films pressed between polished sodium chloride plates. Membranes were either mounted directly in the beam for transmission spectra, or pressed down onto a ZnSe crystal for ATR-reflection spectra.

Raman spectra were recorded on a Perkin Elmer System 2000 FT-Raman / near-IR spectrometer with a laser power of 1200 $\mathrm{mW}$ and a resolution of $4 \mathrm{~cm}^{-1}$. Liquid samples were mounted in the beam in glass vials at ambient temperature and pressure. Membrane samples were mounted directly into the laser beam; several films were pressed together to obtain satisfactory signal to noise ratios.

\section{Raman microscopy}

Raman microscopy was conducted on an Renishaw System 2000 microraman spectrometer with a Ga/Al/As laser (782 nm) generating $13 \mathrm{~mW}$ at the sample. The spectra (resolution of 4 $\mathrm{cm}^{-1}$ ) were recorded with a spatial resolution of a circular area of radius $0.5 \mu \mathrm{m}$ and a depth of $5 \mu \mathrm{m}$. The membrane was pressed between two microscope slides and with a freshly cut thin edge exposed.

\section{Thermogravimetry}

Thermogravimetry and differential thermal analysis (TG/DTA) were carried out simultaneously in flowing oxygen $\left(60 \mathrm{~cm}^{3} \mathrm{~min}^{-}\right.$ $\left.{ }^{1}\right)$ using a Stanton Redcroft STA-781 thermal analyser. Samples (aminated membranes were not dried before analysis) were heated from ambient temperature to $600^{\circ} \mathrm{C}$ at a heating rate of $5^{\circ} \mathrm{C} \min ^{-1}$. All temperatures quoted in the text are sample temperatures measured with a $\mathrm{Pt}: \mathrm{Rh}(13 \%)$ thermocouple in contact with the sample pan. Calcined $\alpha$-alumina was used as the reference material for the DTA. The DTA temperature was calibrated from the endotherms arising from the melting temperatures of tin or zinc samples. Mass losses arising from evaporation of water were accompanied by endotherms in the DTA traces, while mass losses arising from decomposition of the polymers were accompanied by exotherms. All data were collected (5 readings per minute) on an IBM-compatible computer with in-house written software.

\section{Impedance Spectroscopy}

To determine the membrane conductivity, electrochemical impedance spectroscopy (EIS) was used. The alkaline AEMs and Nafion ${ }^{\circledR}-117$ (cut into $1.8 \mathrm{~cm}$ diameter disks) was pressed between two platinum disks ( $1.6 \mathrm{~cm}$ diameter) in a teflon cell. The impedance spectra collected on a Solatron 1260 / 1287 frequency gain analyser / electrochemical interface with a maximum voltage amplitude of $10 \mathrm{mV}$ and a frequency range 1 $\mathrm{Hz}-1 \mathrm{MHz}$. Data manipulation was conducted using ZView software by Scribner Associates. The spectrum of the blank short-circuited cell was also collected and this data was subtracted (as a series circuit) from each of the recorded spectra of the membranes to eliminate cell and wiring resistances and inductances. The corrected spectra were viewed as complex impedance plots with the imaginary component of $Z$ ' on the $y$ axis and the real component of $Z^{\prime}$ on the $x$-axis $\left(Z=Z\right.$ ' $+i Z^{\prime}$ '); the ionic resistance of each membrane was estimated to be the intersection of the $\mathrm{x}$-axis with the extrapolation of the low frequency linear component of each plot.

\section{Chemicals and pre-treatment}

Trimethylamine (Acros Organics, 45\% aqueous solution) and toluene (Fisher, specified reagent, low in sulfur) were used as received. Vinylbenzyl chloride (Dow Chemicals, 97\%, $\mathrm{m} / \mathrm{p}$ ratio of 1.30, stabilised with $75 \mathrm{ppm} 4-t$-butylcatechol and $733 \mathrm{ppm}$ nitromethane, $192 \mathrm{ppm}$ water) was stored in a refrigerator and used without further purification. Nowoflon ${ }^{\circledR}$ PVDF homopolymer film (Nowofol Kunststoffprodukte GmbH \& Co, Germany, $50 \mu \mathrm{m}$ thickness, film formed by extrusion), Solef ${ }^{\circledR}$ 1008 PVDF homopolymer film (Solvay Chemicals Ltd., U.K., $40 \mu \mathrm{m}$ thickness), and FEP film (Goodfellow Ltd., U.K. 50 micron thickness) were used as received with no pre-wash in any solvent. The standard solutions used for IEC determination (Aldrich) were used as received; potassium hydroxide standards were replaced with fresh solution after two months to reduce the build of carbonate and prevent inaccuracies in the titrations. Deionised water was used throughout.

\section{Polymer film irradiation}

The PVDF and FEP were irradiated with a $\gamma$-ray source at the Royal Military College, Cranfield University, Shrivenham, U.K at a temperature of $23 \pm 1{ }^{\circ} \mathrm{C}$ in air. The gamma radiation source
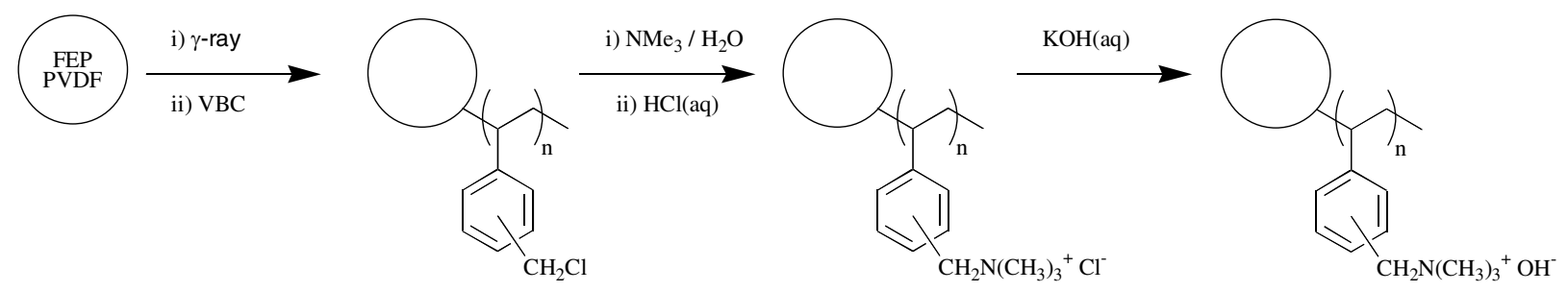

P1 and P2 with PVDF
F1 and $\mathbf{2}$ with FEP

P1NCl and P2NCI
F1NCl and F2NCI

P1NOH and P2NOH
F1NOH and F2NOH

Scheme 1 The radiation-grafting of VBC onto PVDF and FEP and the conversion to the anion-exchange membranes. 
Table 1 Irradiation conditions for the fluoropolymer films.

\begin{tabular}{cccc}
\hline Material & $\begin{array}{c}\text { Dose rate / } \\
\text { kRad h }^{-1}\end{array}$ & Dose time ./ h & $\begin{array}{c}\text { Total dose / } \\
\text { MRad }\end{array}$ \\
\hline $\begin{array}{c}\text { Nowoflon } \\
\text { PVDF }\end{array}$ & 40 & 159 & 6.3 \\
$\begin{array}{c}\text { Solef } \\
\text { GodPDF }\end{array}$ & 40 & 159 & 6.3 \\
Goodfellow & 38 & 165 & 6.3 \\
FEP & & & \\
\hline
\end{tabular}

consists of twenty rods of ${ }^{60} \mathrm{Co}$ encapsulated in steel tubes in an open cylindrical arrangement. In the shielded position the source is housed in a lead and steel flask incorporating a sliding shutter. The flask is located in a cell of internal dimensions $4 \mathrm{~m} \mathrm{x} 3 \mathrm{~m} \mathrm{x}$ $3 \mathrm{~m}$. Typical source activity is $146 \mathrm{TBq}$, giving a maximum dose rate of $12.74 \mathrm{kGy} \mathrm{h}^{-1}$. The exact irradiation conditions used are given in Table 1. The irradiated PVDF and FEP films were stored at $-30^{\circ} \mathrm{C}$ in air after transportation to the University of Surrey under ambient conditions in air. During this study the materials were used within 1 year of irradiation.

\section{Radiation-grafting of VBC onto the irradiated base films}

A general procedure for the grafting reaction is as follows; the exact reaction conditions for the synthesis of the membranes are given in Table 2. The PVDF and FEP (known mass) were loosely rolled up and immersed in excess vinylbenzyl chloride in cylindrical reaction vessels with a ground glass tap; the VBC was then purged with nitrogen (for a minimum of $2 \mathrm{~h}$ ) at room temperature using a long hollow needle before the tap was closed. The grafting reaction was carried out at $60-70^{\circ} \mathrm{C}$ for one week. After this time the now grafted membranes were heated at $60-70^{\circ} \mathrm{C}$ in toluene overnight to remove any unbound poly(vinylbenzyl chloride). The toluene from the membranes was then removed under vacuum $(<1 \mathrm{mmHg})$ for $>4 \mathrm{~h}$. PVDF$g$-PVBC (P1, P2) and FEP- $g$-PVBC (F1, F2) membranes (Table 2) were obtained as brittle translucent white films, where the degree of grafting (d.o.g.) of the materials were calculated as follows (4):

$$
\text { d.o.g. }(\%)=\frac{m_{g}-m_{i}}{m_{i}} \times 100
$$

where $m_{g}$ is the grafted mass and $m_{i}$ is the initial mass of the membranes.

\section{Amination of the grafted membranes}

P1, P2, F1, and F2 were immersed in a $45 \%$ aqueous solution of trimethylamine (Table 2). It was observed that the PVDF-based membranes immediately started to darken; after $24 \mathrm{~h}$ the membranes were weakly translucent with a dark brown colouration. The FEP-based materials did not discolour. After amination, the membranes were soaked in deionised water for $>$ $2 \mathrm{~h}$ (several changes of water) to remove any excess amine, boiled in water for 1 hour, soaked in water overnight, soaked in excess hydrochloric acid (aq, $\left.1 \mathrm{~mol} \mathrm{dm}^{-3}\right)$ for $>48 \mathrm{~h}$ to ensure

Table 2 Grafting and amination experimental conditions

\begin{tabular}{ccccc}
\hline & \multicolumn{3}{c}{ Grafting } & Amination \\
\cline { 2 - 5 } & $\begin{array}{c}\text { Temp / } \\
{ }^{\circ} \mathbf{C}\end{array}$ & $\begin{array}{c}\text { Time / } \\
\text { h }\end{array}$ & $\begin{array}{c}\text { d.o.g. } \\
\mathbf{( \% )}\end{array}$ & Time / h \\
\hline P1 (Nowoflon $\left.{ }^{\circledR}\right)$ & 70 & 164 & 37.8 & $24^{\mathrm{a}}$ \\
P2 (Solef $^{\circledR}$ ) & 70 & 168 & 54.1 & 168 \\
F1 & 60 & 168 & 27.4 & 192 \\
& & & $(25.6)^{\mathrm{b}}$ & \\
F2 & 70 & 168 & 22.7 & 168 \\
\hline
\end{tabular}

a Amination times of 1 week ensured that maximum amination was obtained; it was subsequently established that $24 \mathrm{~h}$ was sufficient. ${ }^{\mathrm{b}}$ The d.o.g. calculated when the small amount of trapped VBC was taken into account (see thermogravimetry of FEP materials later).
Table 3 Ion-exchange capacities (IECs) and water uptakes.

\begin{tabular}{|c|c|c|c|c|}
\hline & \multirow{2}{*}{$\begin{array}{c}\text { IEC } \\
\left(\operatorname{expt.}^{\mathrm{a}} /\right. \\
\operatorname{meq}^{-1}\end{array}$} & \multirow{2}{*}{$\begin{array}{c}\text { IEC } \\
{\text { (calc. })^{b} /}_{\text {meq }^{-1}}\end{array}$} & \multicolumn{2}{|c|}{ Water uptake (\%) } \\
\hline & & & Cl-form & OH- form \\
\hline P1N & 0.31 & 1.6 & $38-52$ & - \\
\hline P2N & 0.71 & 2.0 & $56-74$ & $70-98$ \\
\hline F1N & 0.96 & 1.3 & $38-48$ & $47-53$ \\
\hline F2N & 0.71 & 1.1 & - & $31-35$ \\
\hline
\end{tabular}

${ }^{a}$ The experimental IECs are for the chloride-forms. ${ }^{b}$ The calculated IEC values give the maximum IEC expected assuming $100 \%$ amination and no residual water remaining on drying.

the chloride form, soaked in water for $>48 \mathrm{~h}$ with several water changes, and finally stored in water to prevent dehydration. The aminated PVDF- $g$-PVBTMACl membranes, P1NCI and P2NCl, in the chloride form were obtained as a dark brown, faintly translucent, flexible membranes. The FEP-g PVBTMACl membranes, F1NCl and F2NCl, were obtained as flexible colourless, transparent membranes.

The PVDF- and FEP- $g$-PVBTMAOH membranes, P1NOH, P2NOH, F1NOH, and F2NOH respectively were generated by immersion in a large excess of potassium hydroxide (aq, $1 \mathrm{~mol}$ $\mathrm{dm}^{-3}$ ) for $>48 \mathrm{~h}$ and then in water for $>48 \mathrm{~h}$ with frequent water changes to remove any trapped potassium hydroxide. The PVDF-based materials were brittle.

\section{Membrane Property Determinations}

\section{Ion-exchange capacities (IECs)}

Ion-exchange capacities (IECs) of the chloride-forms ${ }^{\dagger}$ were determined as follows. The materials to be analysed were converted to the hydroxide forms and immersed in $20 \mathrm{~cm}^{3}$ of hydrochloric acid standard (aq, $0.1 \mathrm{~mol} \mathrm{dm}^{-3}$, Aldrich) for $>24$ h. The solutions were then back titrated with potassium hydroxide standard (aq, $0.1 \mathrm{~mol} \mathrm{dm}^{-3}$, Aldrich) using a Metrohm 716 DMS Titrino. The titrations were conducted dynamically with a minimum addition of potassium hydroxide of $0.002 \mathrm{~cm}^{3}$ and a maximum titration rate of $0.5 \mathrm{~cm}^{3} \mathrm{~min}^{-1}$. End points were determined from maxima in the differential titration curve. This procedure was conducted three times for each membrane and a blank $\left(20 \mathrm{~cm}^{3}\right.$ of hydrochloric acid (aq, $\left.0.1 \mathrm{~mol} \mathrm{dm}^{-3}\right)$ with no membrane) was run alongside each batch. There was evidence of carbonate formation in the potassium hydroxide standard solutions (a small initial end point at $\mathrm{pH} \sim 4.5$ ) but this was determined not to affect accuracies as the blank runs showed errors of $<0.2 \%$. The amount of hydroxide anions in the membranes was calculated from the difference between the initial amount of hydrochloric acid in which the membranes were soaked and the amount of hydrochloric acid remaining as determined from the titration. After titration the membrane samples are washed in water, soaked in hydrochloric acid (aq, 1 mol $\mathrm{dm}^{-3}$ ) for $>48 \mathrm{~h}$ to regenerate the chloride anion forms, and then soaked in water for $>48 \mathrm{~h}$ with frequent changes to remove any trapped acid. The samples were then dried at $\mathrm{RH}=0 \%$ in a desiccator over anhydrous calcium chloride at ambient temperatures for $>1$ week. This drying methodology was preferred, to be consistent with the method adopted for later water uptake experiments. The IECs were calculated as below (5):

$$
\text { IEC / eq } g^{-1}=\frac{n_{i}\left(H^{+}\right)-n_{f}\left(H^{+}\right)}{m_{d r y}\left(C l^{-}\right)}
$$

where $n_{i}\left(H^{+}\right)$is the amount of acid the membrane was soaked in, $n_{f}\left(H^{+}\right)$is the amount of acid remaining as determined by the titration, and $m_{d r y}\left(\mathrm{Cl}^{-}\right)$is the mass of the dried membrane in the chloride-form. The IECs of the aminated membranes are reported in Table 3 and presented graphically in Fig. 1.

Long-term thermal stability 


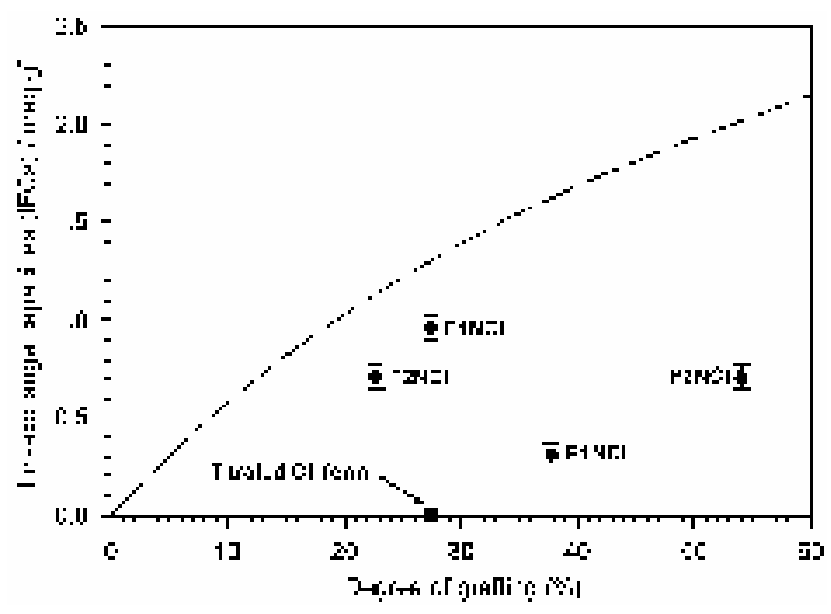

Fig. 1 The IECs for the VBC grafted and aminated membranes (chlorideforms). The errors displayed correspond to the largest error calculated from the tolerances of the pipettes (class A) and variations in weight of the dried membranes (which gain mass from atmospheric water on transport between the desiccator and the balance). The dashed line indicates the maximum theoretical IEC for each d.o.g.

Samples of membrane F2NOH were heated at $60^{\circ} \mathrm{C}$ and $100^{\circ} \mathrm{C}$ in water; the IECs ${ }^{\ddagger}$ of samples, removed after varying periods of time, were then recorded.

\section{Water (Methanol) uptakes}

The wet aminated samples were quickly weighed in both the chloride- and hydroxide-forms to obtain the hydrated mass. The samples were then dried at $\mathrm{RH}=0 \%$ in a desiccator over anhydrous calcium chloride for 1 week at ambient temperatures. It was determined that this drying methodology gave the same level of drying as treatment in a vacuum oven at $80^{\circ} \mathrm{C}$ for 4 hours; the former method was adopted as it avoids elevated temperatures, which may cause displacement of the trimethylamine functions by the hydroxide anions. The dried masses were recorded and the water uptake was calculated (6):

$$
W U(\%)=\frac{m_{h y d}-m_{d r y}}{m_{d r y}} \times 100
$$

where $m_{h y d}$ is the hydrated mass and $m_{d r y}$ is the dry mass. The water uptakes are reported in Table 3.

For dehydration and rehydration testing (with water), a sample (of known dimensions) in the hydrated aminated hydroxide-form was dehydrated at $\mathrm{RH}=0 \%$ for 1 week, rehydrated by immersion in water at room temperature for 1 week and then dehydrated again as before. The volume and thickness of the membrane sample was measured at each stage; the whole process was duplicated twice more to obtain average values for a batch of 3 membranes of the same sample.

For methanol uptake (conducted for F1NOH and F2NOH), the dried membranes (week $\mathrm{RH}=0 \%$ ) were weighed and the thicknesses recorded. The membranes were then soaked in pure methanol for 2 days, then were again weighed and the thicknesses recorded (after removing any surface methanol). Calculation of the methanol uptakes was identical to that for the water uptakes.

\section{AEMs based on PVDF films}

\section{Radiation grafting and amination}

VBC was grafted onto both Nowoflon ${ }^{\circledR}$ and Solef ${ }^{\circledR}$ PVDF films to form P1 (d.o.g. $=39 \%$ ) and P2 (d.o.g. $=54 \%$ ) respectively. The Solef ${ }^{\circledR}$ PVDF lead to a higher d.o.g. as the thinner PVDF film allowed more monomer to permeate into the membrane to react before the radicals were destroyed due to the elevated temperature $\left(70^{\circ} \mathrm{C}\right) . \mathbf{P 1}$ and $\mathbf{P 2}$ were subsequently aminated to form the benzyltrimethylammonium chloride analogues $\mathbf{P 1 N C l}$ and P2NCl respectively, which were obtained as a dark brown, translucent, flexible membranes. Conversion to the hydroxideforms (P1NOH and P2NOH) resulted in brittle materials of no practical use; this brittleness suggests degradation of the polymer backbone. The IECs (Table 3) were significantly lower than the levels predicted by calculation. Again, this correlates with previous observations of structural instability on treatment with alkali.

The observed structural instability suggests degradation of the PVDF backbone. Liberation of HF from PVDF has been reported on treatment with hot, concentrated alkali solutions in the presence of surfactants. ${ }^{19}$ This would explain lowered IECs, as the liberated HF would neutralise any hydroxide anions present. For comparison, P1 was immersed in aqueous potassium hydroxide $\left(1 \mathrm{~mol} \mathrm{dm}^{-3}\right)$; no deterioration or discolouration was observed. Furthermore, no obvious increased brittleness or discolouration was observed when $\gamma$-irradiated PVDF was soaked in alkali for extended periods of time (> 1 week). These observations indicate a second mechanism is operating, where the brittleness originates in the amination reaction; subsequent treatment with hydroxide only acts to amplify this degradation process. Further evidence for this was that a $\gamma$-irradiated, but non-grafted, piece of PVDF turned light brown when immersed in amine solution. A third scenario is where the hydroxide ions are displacing the amine via a nucleophilic substitution. This is consistent with the lowered IECs that were observed, but would not be expected to lead to brittle materials. NMR spectroscopic studies were conducted to clarify the situation.

\section{Characterisation by vibrational spectroscopy}

Useful information on the PVDF backbone was obtained from the Raman spectra of the radiation-grafted AEMs produced (Fig. 2). The Raman bands of PVDF have been previously assigned by Tadokoro et $a l^{20}$ The Raman bands of styrene grafted PVDF membranes have also been reported extensively ${ }^{21}$ and can be directly compared to those of the AEMs here.

For PVDF, the strong $\mathrm{CF}_{2}$ bend + CCC skeletal out-of-phase combination band at $612 \mathrm{~cm}^{-1}$, the $\mathrm{CF}_{2}$ bend at $537 \mathrm{~cm}^{-1}$, and the $\mathrm{CF}_{2}$ bend $+\mathrm{CF}_{2}$ wag in-phase combination band at $486 \mathrm{~cm}^{-1}$ were indicative of the $\alpha$-phase of PVDF with a trans-gauchetrans-gauche chain conformation. The absence of bands associated with the $\beta$-crystalline phase of PVDF (all trans chain conformation), located at $513 \mathrm{~cm}^{-1}$ and 840 (present as a weak

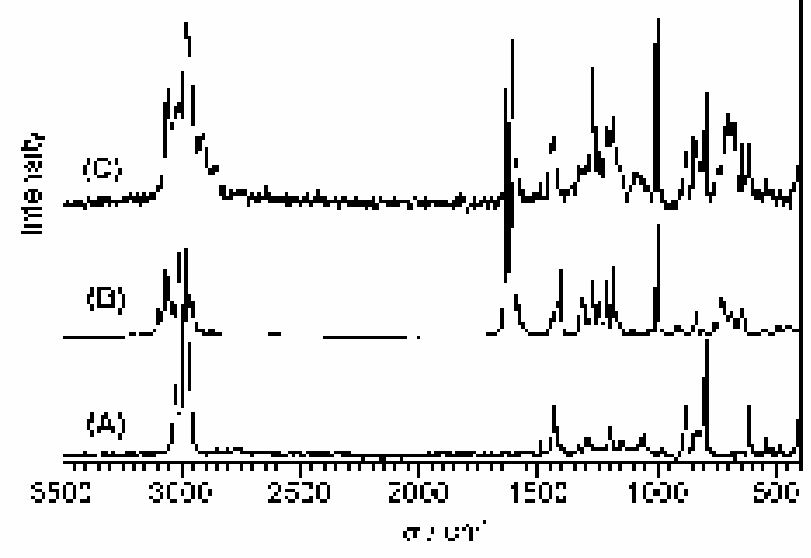

Fig. 2 The FT-Raman spectra of (A) Solef ${ }^{\circledR}$ PVDF, (B) VBC, and (C) P2. 
band in the spectrum of the $\alpha$-form but expected to be strong with the $\beta$-form), indicated this phase was not present in significant quantities.

The Raman spectra for both $\mathbf{P 1}$ and $\mathbf{P 2}$ (Fig. 2) were similar. The spectra contained no evidence of any morphological change to the $\beta$-crystalline form with the PVDF component; this is in agreement with the styrene grafted PVDF membranes previously reported. ${ }^{21}$ The new bands observed were all present in the Raman spectrum of poly(vinylbenzyl chloride). The most significant of these were strong bands at $1613,1269,1003 \mathrm{~cm}^{-1}$, the latter of which was the most intense and was also present as the $v_{12}$ band in the Raman spectrum of poly(styrene). ${ }^{22}$ Bands at 1633 and $1408 \mathrm{~cm}^{-1}$ in the spectrum of VBC associated with the $\mathrm{C}=\mathrm{C}$ str. and in plane bend respectively ${ }^{23}$ were not present in the spectra of the grafted materials. The only difference between the Raman spectra of $\mathbf{P 1}$ and $\mathbf{P 2}$ was that the poly(vinylbenzyl chloride) bands for the latter were more intense relative to the PVDF bands, confirming the higher d.o.g. The Raman spectra for the aminated samples could, unfortunately, not be recorded due to the laser burning the dark coloured samples.

\section{Solid state NMR spectroscopy}

The ${ }^{19} \mathrm{~F}$ solid state NMR spectrum of PVDF has been reported extensively in the literature. ${ }^{24}$ The ${ }^{13} \mathrm{C}$ spectra of PVDF, ${ }^{25} \mathrm{PVDF}$ grafted with polystyrene and then sulfonated, ${ }^{26}$ and poly(vinylbenzyl chloride) $)^{27}$ have also been reported. The following interpretation of the solid state NMR spectra of the PVDF-based materials will refer to these previous spectroscopic studies. The ${ }^{19} \mathrm{~F}\left\{{ }^{1} \mathrm{H}\right\}$ DP-MAS spectrum of Solef ${ }^{(B)} 1008$ PVDF homopolymer (Fig. 3) showed the expected signals attributed to fluorine atoms in amorphous domains $\left(F_{2}, \delta_{\mathrm{F}}=-91\right)$, crystalline domains $\left(F_{1}, \delta_{\mathrm{F}}=-82\right.$, and $F_{3}$, a shoulder on the $\delta_{\mathrm{F}}=-91$ signal with a position of $\delta_{\mathrm{F}}=-96$ located by deconvoloution), and in the head-head and tail-tail defect domains $\left(D_{l}, \delta_{\mathrm{F}}=-113\right.$ and $D_{2}$, $\delta_{\mathrm{F}}=-115$ respectively).

These signals remain largely unchanged on radiation-grafting with VBC to form P2, though a small amount of broadening indicates small morphological changes. However, substantial changes in these signals were observed on amination (P2NCl); the $F_{3}$ signal increased in intensity while both the $F_{2}$ and $F_{3}$ signals broadened. The $\mathrm{F}_{1}$ signal remained relatively unchanged. These observations confirm that amination has modified the PVDF backbone. A small shoulder signal in the defect region at $\delta_{\mathrm{F}}=-119$ was also observed. This signal dramatically increased

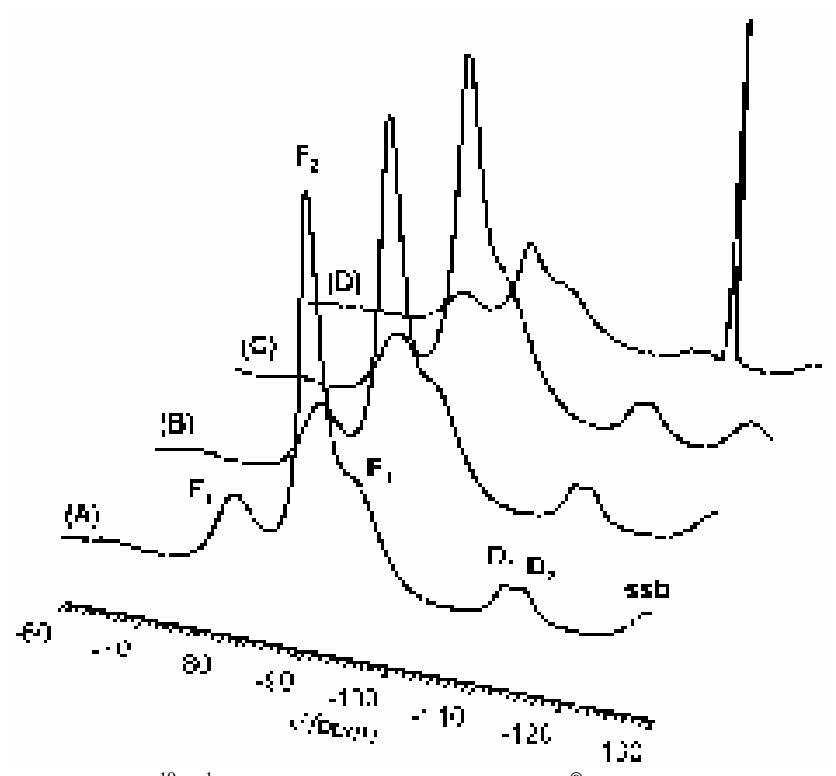

Fig. 3 The ${ }^{19} \mathrm{~F}\left\{{ }^{1} \mathrm{H}\right\}$ DP-MAS NMR of (A) Solef ${ }^{\circledR}$ PVDF, (B) P2, (C) P2NCl, and (D) P2NOH. ssb = spinning sideband.

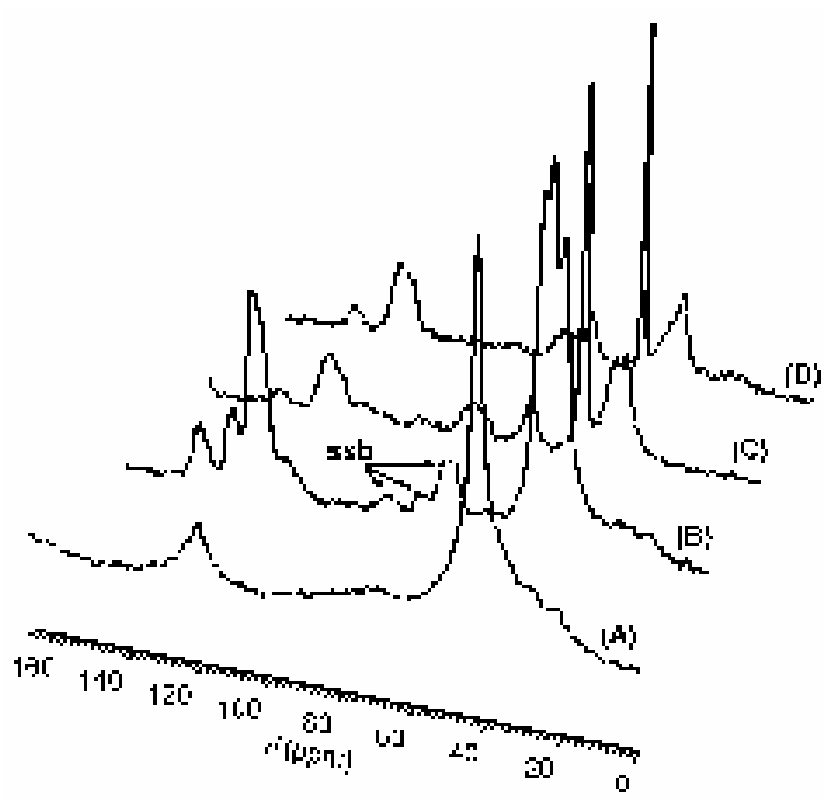

Fig. 4 The ${ }^{13} \mathrm{C}\left\{{ }^{1} \mathrm{H}\right\}$ CP-MAS NMR of (A) Solef ${ }^{\circledR}$ PVDF, (B) P2, (C) P2NCl, and (D) P2NOH. ssb = spinning sideband.

in intensity on conversion to $\mathbf{P 2 N O H}$, and the narrow linewidth suggesting a mobile species; when it is recalled that this is the stage that the materials become brittle, it is evident that the backbone had been severely disrupted on treatment with hydroxide and that this process began on amination (with the appearance of this signal as a small shoulder). In terms of signal area in the spectrum of $\mathbf{P 2 N O H}$, the total area of signals was is dominated by the original PVDF signals, although $F_{2}$ had decreased significantly in intensity.

The $\underline{C F}_{2}$ signals at $\delta_{\mathrm{C}}=120$ obtained in the ${ }^{13} \mathrm{C}\left\{{ }^{1} \mathrm{H}\right\}$ CP-MAS spectrum of PVDF (Fig. 4) were weak as ${ }^{19} \mathrm{~F}$ decoupling was not possible on the 2-channel instrument, which allows only proton decoupling in carbon spectra. The intense $\mathrm{CH}_{2}$ carbon signal for PVDF appeared as expected at $\delta_{\mathrm{C}}=44$. The spectrum of $\mathbf{P 2}$ comprises of the spectrum of poly(vinylbenzyl chloride) superimposed on the spectrum of PVDF as expected. In the aromatic region, signals at $\delta_{\mathrm{C}}=146$ (the ipso-carbon attached to the aliphatic backbone carbons), $\delta_{\mathrm{C}}=136$ (the ipso-carbon attached to the $\mathrm{CH}_{2} \mathrm{Cl}$ group), and $\delta_{\mathrm{C}}=129$ (the remaining aromatic carbons) are all observed; the aliphatic region reveals signals at $\delta_{\mathrm{C}}=46\left(\underline{\mathrm{CH}}_{2} \mathrm{Cl}\right), \delta_{\mathrm{C}}=44\left(\mathrm{PVDF} \underline{\mathrm{CH}}_{2}\right)$, and $\delta_{\mathrm{C}}=41$ $\left(\mathrm{CH}_{2} / \mathrm{CH}\right.$ groups from the polymerised vinyl groups). The other bands observed were confirmed as spinning sidebands by observing the shift in positions of these sidebands on varying the magic angle spinning rate.

New carbon signals appeared on amination. An intense, narrow signal at $\delta_{\mathrm{C}}=53$ was attributed to the $\mathrm{N}\left(\mathrm{CH}_{3}\right)$ methyl groups; this assignment was confirmed by the lone presence of this band in the same spectrum recorded using a dipolar-dephasing pulse sequence. The band at $\delta_{\mathrm{C}}=69$, due to the $\mathrm{CH}_{2} \mathrm{NMe}_{3}$ carbon (this band occurs at $\delta_{\mathrm{C}}=70$ in the solution state NMR of (vinylbenzyl)trimethylammonium chloride), was confirmed as an isotropic signal with its continued presence in the same spectrum recorded with an added TOSS (Total Suppression of Spinning Sidebands) pulse sequence. The ${ }^{13} \mathrm{C}\left\{{ }^{1} \mathrm{H}\right\}$ spectrum of P2NOH was similar to the spectrum of $\mathbf{P 2 N C l}$; both were recorded using identical acquisition conditions and parameters. The $\delta_{\mathrm{C}}=53 \mathrm{~N}\left(\mathrm{CH}_{3}\right)_{3}$ signal remained, confirming the presence of trimethylammonium groups; it was narrower than found with the chloride-form suggesting the $\mathrm{N}\left(\mathrm{CH}_{3}\right)$ groups were part of a more mobile phase. The PVDF backbone $\underline{\mathrm{CH}}_{2}$ signal at $\delta_{\mathrm{C}}=44$ had decreased in intensity, appearing as a shoulder to the band at $\delta_{C}=41$, which is again consistent with the breakup of the PVDF backbone. 
The $\quad{ }^{15} \mathrm{~N}\left\{{ }^{1} \mathrm{H}\right\} \quad$ CP-MAS NMR spectrum of (vinylbenzyl)trimethylammonium chloride showed a single signal located at $\delta_{N}=-329$ (Fig. 5); this signal remains for both P2NCl and P2NOH. However, the signal to noise ratio for the hydroxide-form was significantly poorer (Fig 5C). This may arise from unsuitable acquisition conditions; more likely, it indicates the presence of less nitrogen in the sample, which is consistent with the observed lowered IECs.

\section{Summary for PVDF-based membranes}

PVDF-based material grafted successfully with the VBC monomer. The amination and alkaline exchange processes, however, physically degraded the PVDF backbone resulting in very brittle materials when in the hydroxide-form; these materials exhibited low IECs and would be unsuitable for use in any kind of fuel cell or electrochemical device. These results also show that caution is required with the PVDF-based AEMs developed by Svarfar et al., to prevent any contact with any alkali. ${ }^{11 a}$ A solution to this structural instability would be the replacement of the partially fluorinated PVDF base polymer with a fully fluorinated analogue; this would not allow dehydrofluorination of the backbone, which occurs with the hydrogen-containing PVDF backbone. ${ }^{19}$ An ideal candidate is poly(tetrafluoroethene-co-hexafluoropropene) (FEP) which has been successfully grafted with poly(styrene), using the preirradiation grafting technique, by Scherer et al. ${ }^{13}$.

\section{AEMs based on FEP films}

\section{Radiation grafting and amination}

VBC was grafted onto FEP (Scheme 1) to form F1 (27\% d.o.g.) and F2 (22\% d.o.g). Grafting at $60^{\circ} \mathrm{C}$ gave a slightly higher d.o.g. than grafting at $70^{\circ} \mathrm{C}$; the lower temperature permitted grafting to continue longer before the radicals were quenched (normally via intrapolymer cross-linking) ${ }^{11 a}$ These materials were subsequently aminated to form the respective (benzyl)trimethylammonium chloride analogues, F1NCl and F2NCl respectively, which were obtained as transparent, flexible membranes. Conversion to the hydroxide-forms resulted in no discolouration or brittleness. The thicknesses of the resulting membranes when grafted and aminated are presented in Table 4. A general trend of swelling was observed on going from the FEP

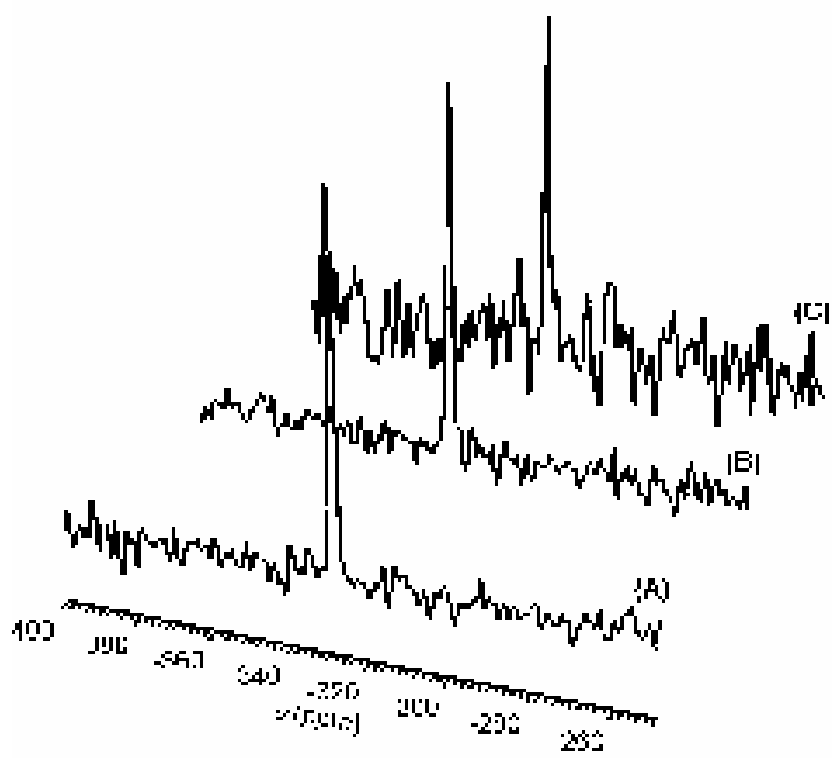

Fig. 5 The ${ }^{15} \mathrm{~N}\left\{{ }^{1} \mathrm{H}\right\}$ CP-MAS NMR of

(A) (vinylbenzyl)trimethylammonium chloride, (B) $\mathbf{P 2 N C l}$, and (C) P2NOH
Table 4 The ranges of thicknesses observed with the FEP-based membranes.

\begin{tabular}{cccc}
\hline & $\boldsymbol{t}^{\mathbf{a}} / \boldsymbol{\mu} \mathbf{m}$ & & $\boldsymbol{t}^{\mathbf{a}} / \boldsymbol{\mu m}$ \\
\hline FEP & $48-50$ & - & - \\
F1 & $65-67$ & F2 & $58-60$ \\
F1NCl & $80-90$ & F2NCl & - \\
F1NOH & $90-100$ & F2NOH & $75-82$ \\
\hline
\end{tabular}

${ }^{a}$ Measured with micrometer; four readings were taken on different samples of each material.

to the grafted materials and finally to the aminated membranes. There was an increase in thickness on going from the chlorideform to the hydroxide-form; this is consistent with the larger hydration spheres expected for the hydroxide anions.

The results from hydration/dehydration testing for $\mathbf{F 2 N O H}$ are presented in table 5 and show the variation of thickness and volume on going from the hydrated to the dehydrated form and then to a rehydrated and a final dehydrated form. There was on average a $32 \%$ reduction in volume and a $23 \%$ reduction in thickness on going from the hydrated to the dehydrated form for the first cycle. This was reproducible on further rehydration and dehydration.

Table 5 Volumes and thickness of F2NOH on dehydration / rehydration.

\begin{tabular}{lcccc}
\hline & Hydrated & Dehydrated & Rehydrated & Dehydrated \\
\hline $\mathrm{V} / \mathbf{c m}^{3}$ & 0.031 & 0.021 & 0.031 & 0.020 \\
$\boldsymbol{t} / \boldsymbol{\mu m}$ & 78 & 60 & 77 & 60 \\
\hline
\end{tabular}

The methanol uptakes were $37 \%$ for F1NOH and $33 \%$ for F2NOH. The thicknesses of methanol swollen F1NOH and F2NOH were 82 and $81 \mu \mathrm{m}$ respectively. The methanol uptake and swollen thickness for the lower d.o.g. membrane F2NOH were similat to the values found with water; however, for the higher d.o.g. F1NOH, the methanol values were significantly lower.

The ion-exchange capacities IECs (Table 3, Fig. 1) were lower than the levels predicted by calculation; ${ }^{8}$ however, the values were significantly higher than those found with the PVDF-based membranes with higher degrees of grafting. Nafion $11 x$ series of membranes have an equivalent weight of $1100 \mathrm{~g} \mathrm{~mol}^{-1}(\equiv 0.91$ meq $\left.\mathrm{g}^{-1}\right)$; F1NCl yielded a higher IEC. As a final check on the validity of the IEC determination technique, F1NCl was titrated directly (i.e. without conversion to the hydroxide form) with hydrochloric acid standard $\left(0.1 \mathrm{~mol} \mathrm{dm}^{-3}\right)$. An IEC of zero, as expected, was obtained indicating that the values of the IECs obtained were due to the $\mathrm{OH}^{-}$ions only, and not some other sidereaction.

\section{Characterisation by vibrational spectroscopy}

The vibrational spectra of FEP are very similar to those of poly(tetrafluoroethene), PTFE, the main component of FEP. The infrared (ATR) spectrum of FEP showed two strong bands at 1205 and $1147 \mathrm{~cm}^{-1}$ which were assigned to $v_{\text {as }}\left(\mathrm{CF}_{2}\right)^{28,29}$ and a weak band at $983 \mathrm{~cm}^{-1}$, not present for PTFE, assigned to the C$\mathrm{F}$ stretch of the $\mathrm{CF}_{3}$ pendant group. ${ }^{30}$ The transmission spectrum showed a $\mathrm{CF}_{2}$ combination band at $2373 \mathrm{~cm}^{-1}$. ${ }^{1}$ The Raman spectrum (Fig. 6) shows only bands that have been previously observed for PTFE; $;^{29}$ the strongest band observed is the $v_{\mathrm{s}}\left(\mathrm{CF}_{2}\right)$ band at $733 \mathrm{~cm}^{-1}$.

The Raman spectrum of $\mathbf{F 1}$ contained all the signals assignable to the FEP base component. New bands were observed; these were present in the Raman spectrum of poly(vinylbenzyl chloride). The most significant of these were strong bands at $1613,1268,1003 \mathrm{~cm}^{-1}$, the latter of which was the most intense and was also present as the $v_{12}$ band in the spectrum of poly(styrene). ${ }^{22}$ There was evidence of a small amount of residual VBC monomer in the material (a band at $1632 \mathrm{~cm}^{-1}$ in the Raman spectrum of F1 - see thermogravimetry of F1 later); this feature corresponds to the strong $\mathrm{C}=\mathrm{C}$ band located in the 
Raman spectrum of VBC, which does not occur in the spectrum of poly(vinylbenzyl chloride).

It was possible, unlike with the PVDF-based materials, to record Raman spectra for the aminated samples; The Raman spectrum of (vinylbenzyl)trimethylammonium chloride was recorded for comparative reasons; there were three weak bands at 759, 978 and $1484 \mathrm{~cm}^{-1}$ that were not present in the Raman spectrum of VBC. These three bands were also visible in the Raman spectra of both the F1NCl and F1NOH. This suggests amination had progressed via a direct nucleophillic substitution as expected; The disappearance of the $\mathrm{CH}_{2} \mathrm{Cl}$ band at $1268 \mathrm{~cm}^{-1}$, present in the spectrum of $\mathbf{F 1}$, for the aminated samples confirms this. There was no longer any evidence of $\mathrm{C}=\mathrm{C}$ bonds suggesting all trapped monomer (VBC) had been aminated and released into aqueous solution on workup.

\section{Raman microscopic studies (graft penetration)}

The measure of graft penetration deduced from Raman microscopy is based on methods, which have been reported earlier. ${ }^{32} \mathrm{~A}$ profile of the penetration of VBC component throughout the thickness of $\mathbf{F} 1$ is presented in Figure 7. This was measured from the ratio of the areas of two selected Raman bands which relate to the two separate components (the poly(vinylbenzyl chloride) band at $1002 \mathrm{~cm}^{-1}$ and the FEP band at $\left.387 \mathrm{~cm}^{-1}\right)$. Graft penetration was good with only a $38 \%$ drop in the concentration of VBC component in the centre of the membrane compared with the membrane surface. Graft penetration is expected to improve with further optimisation of the grafting process with higher d.o.g. The dip in VBC concentration within the membrane thickness is evidence that the grafting-front mechanism is operating as described by Scherer $e t$

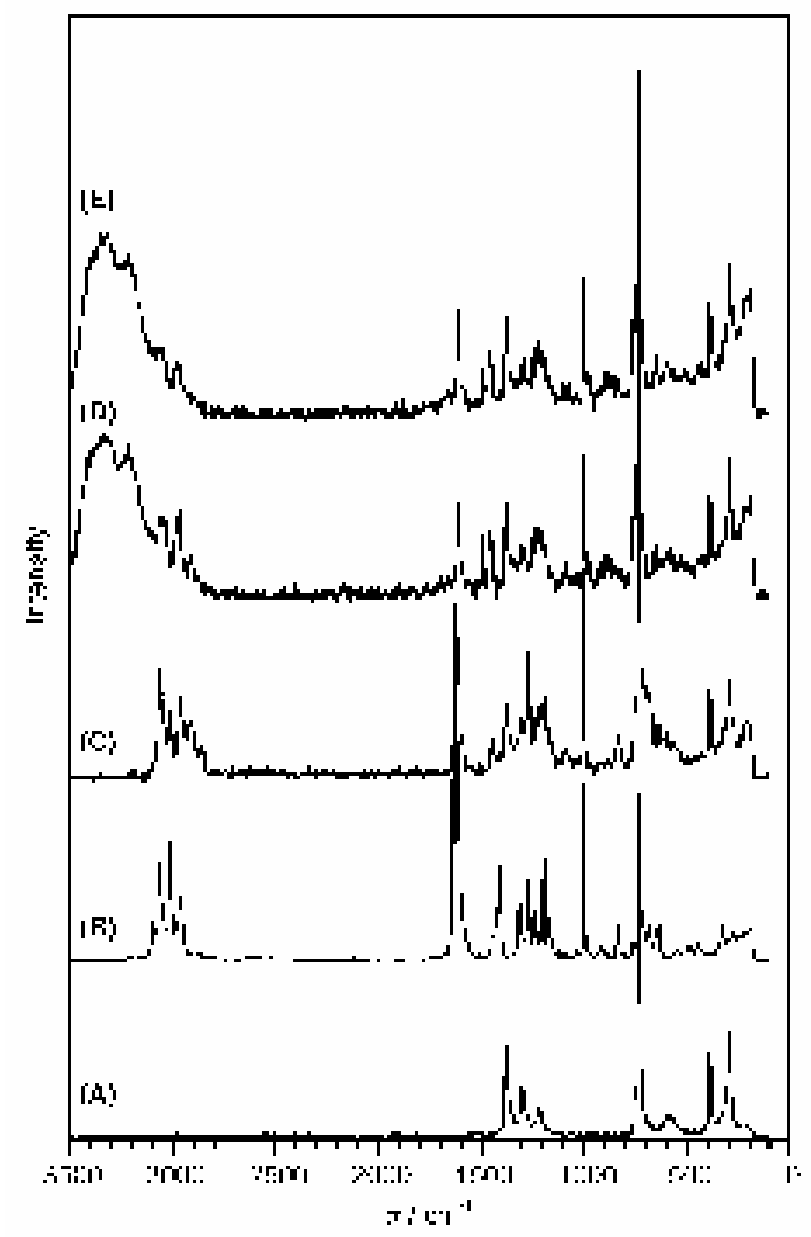

Fig. 6 The FT-Raman spectra of (A) FEP, (B) VBC, (C) F1, (D) F1NCl, and (E) F1NOH.

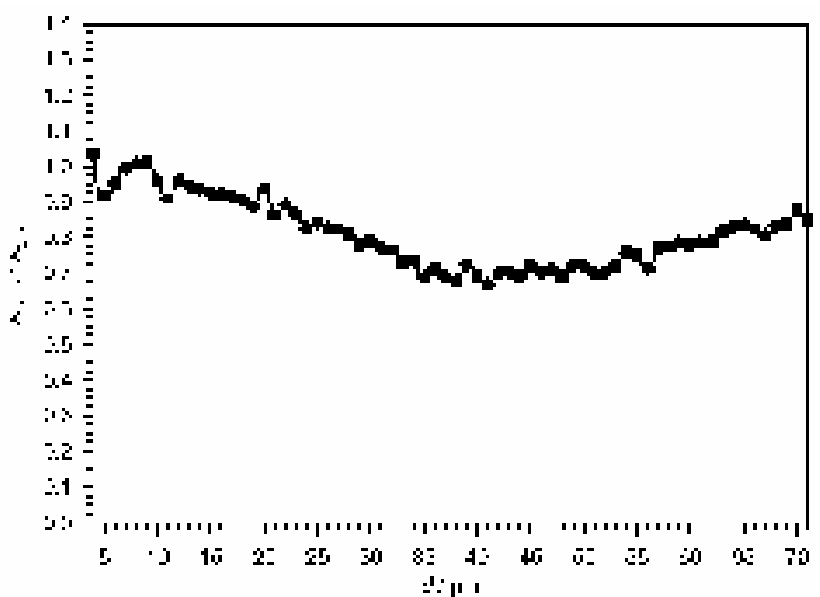

Fig. 7 The variation in the ratio of areas of the poly(vinylbenzyl chloride) band at $1002 \mathrm{~cm}^{-1}$ and the FEP band at $387 \mathrm{~cm}^{-1}$ across the thickness of membrane $\mathbf{F 1}$.

al. previously with styrene grafted films. ${ }^{13 a}$ The different levels of grafting between each surface of the membrane may be an artefact arising from the rolling of the membrane during the grafting of VBC onto the FEP and indicates the need for further optimisation of the grafting procedure. This optimisation work is currently underway.

\section{Solid state NMR spectroscopy}

The ${ }^{19} \mathrm{~F}\left\{{ }^{1} \mathrm{H}\right\}$ DP-MAS NMR spectrum of the FEP film (Goodfellow, U.K. 50 micron thickness) is reported here for comparison with the grafted and aminated membranes (Fig. 8). The following features were observed and have been reported elsewhere. ${ }^{33}$ The intense signal at $\delta_{\mathrm{F}}=-122$ was attributed to the $\mathrm{CF}_{2}$ backbone (also found in the NMR spectrum of PTFE). Smaller signals at $\delta_{\mathrm{F}}=-72\left(-\mathrm{CF}_{3}\right.$ groups $), \delta_{\mathrm{F}}=-112\left(\mathrm{CF}_{2}\right.$ next to $\mathrm{CF}\left(\mathrm{CF}_{3}\right)$ groups $)$, and $\delta_{\mathrm{F}}=-186\left(\mathrm{CF}\left(\mathrm{CF}_{3}\right)\right)$ were all observed. These signals did not vary on grafting or amination; this confirms that, unlike previously found with the PVDF-based materials, the FEP backbone remained intact with the occurrence of no significant morphological changes. The lack of variation in ${ }^{19} \mathrm{~F}$ linewidths also correlates with observations from DSC studies by Scherer et al. that grafting of styrene occurs in the amorphous region of the FEP film, leaving the inherent

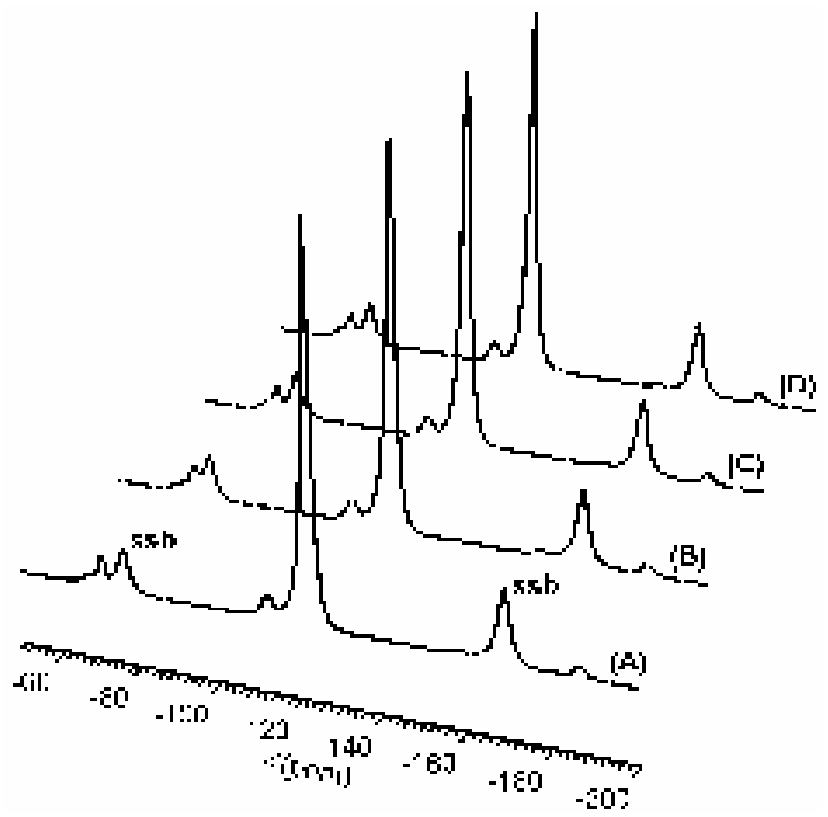

Fig. 8 The ${ }^{19} \mathrm{~F}\left\{{ }^{1} \mathrm{H}\right\}$ DP-MAS NMR of (A) FEP, (B) F1, (C) F1NCl, and (D) F1NOH. ssb = spinning sideband. 


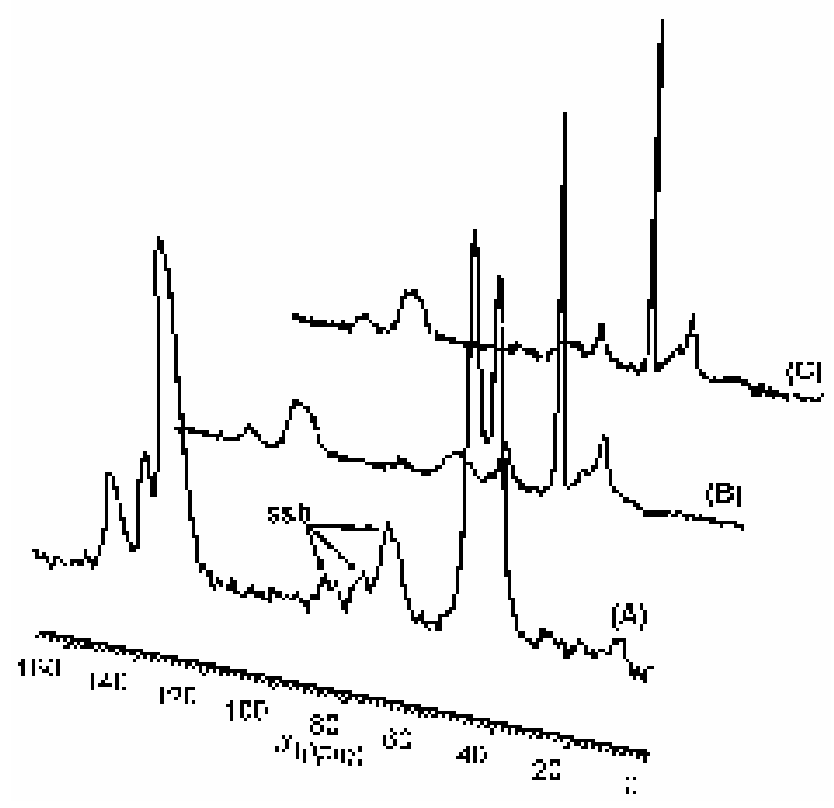

Fig. 9 The ${ }^{13} \mathrm{C}\left\{{ }^{1} \mathrm{H}\right\}$ CP-MAS NMR of (A) F1, (B) F1NCl, and (C) F1NOH. ssb = spinning sideband.

crystallites intact. $^{34}$

The ${ }^{13} \mathrm{C}\left\{{ }^{1} \mathrm{H}\right\}$ CP-MAS spectrum of FEP showed a flat baseline due to the lack of available F-decoupling; the carbon spectrum for F1 (Fig. 9) was simpler than the corresponding spectrum of the PVDF analogues because of this lack of FEP carbon signals. All the signals expected for poly(vinylbenzyl chloride) ${ }^{27}$ were present (see NMR data for the PVDF-based materials). On amination, the $\mathrm{N}\left(\mathrm{CH}_{3}\right)$ carbons were again evident at $\delta_{\mathrm{C}}=53$ as were the $\mathrm{CH}_{2} \mathrm{~N}$ carbons at $\delta_{\mathrm{F}}=69$. The $\mathrm{CH}_{2} \mathrm{Cl}$ signal had also greatly reduced in intensity compared with the spectrum of $\mathbf{F 1}$. There was no visible difference between the spectra of F1NCl and F1NOH.

The ${ }^{15} \mathrm{~N}\left\{{ }^{1} \mathrm{H}\right\}$ CP-MAS spectra for both forms of the aminated product again showed a single signal at $\delta_{\mathrm{N}}=-329$. The signal to noise ratio did not decrease to such an extent on conversion to the hydroxide form, when compared with the PVDF analogues (Fig 5), indicating improved stability.

\section{Thermogravimetry}

The TG traces for FEP, F1, F1NCl, and F1NOH are presented in Fig. 10. Oxygen was used in thermogravimetry as it was expected that the materials would exhibit the least stability in this regime. Also, as fuel cells are run with air/oxygen, this would give a more true to life picture than if nitrogen, as reported with the stability of styrene-grafted and sulfonated FEP proton conducting membranes, ${ }^{35}$ had been used. FEP exhibited two-step degradation (with two separate exotherms) commencing at $403^{\circ} \mathrm{C}$. In the TG trace of $\mathbf{F 1}$ there was a small mass loss $(1.4 \%)$ in the range $92-218^{\circ} \mathrm{C}$; this confirms the presence of a small amount of trapped VBC monomer and indicates an actual d.o.g of $25.6 \%$ for $\mathbf{F 1}$ instead of the initially measured $27.4 \%$ (once aminated, the trapped monomer was automatically removed by dissolution in water on workup). F1 degraded in two distinct steps, with the first step (this may consist of two unresolved decomposition steps, but for simplicity will be considered as one) due to degradation of the poly(vinylbenzyl chloride) component; the presence of two distinct degradation steps indicates incompatibility of the poly(vinylbenzyl chloride) with the FEP matrix, which results from the formation of phase-separated microdomains. ${ }^{36}$ It was also observed that the presence of poly(vinylbenzyl chloride) grafts does not change the inherent decomposition of the FEP component, which occurs rapidly (along with a large associated exotherm in the DTA trace) at the same temperature (Fig. 10) .
Table 6 Short-term temperature stabilities in oxygen.

\begin{tabular}{cc}
\hline & \\
\hline FEP & Decomposition onset ${ }^{\mathrm{a}} /{ }^{\circ} \mathbf{C}$ \\
F1 & 398 \\
F1NCl & 218 \\
F1NOH & 194 \\
\hline
\end{tabular}

${ }^{a}$ Estimated (error of $\pm 10^{\circ} \mathrm{C}$ ) from the onset temperature of the first mass loss due to polymer degradation in the TGA profiles. For the aminated samples (recorded wet), the first mass loss observed corresponded to water loss and was not considered.

The percentage mass loss between 218 and $419^{\circ} \mathrm{C}$ relating to loss of poly(vinylbenzyl chloride) was $14.0 \%$, which was less that the degree of grafting (25.6\%) for F1. This indicates that, as was found with styrene-grafted FEP, ${ }^{36,37}$ a significant fraction of aromatics remain despite the elevated temperatures.

The short-term temperature stabilities (in oxygen) of the FEP- $g$ VBC-based materials are presented in Table 6. There was a general trend of decreasing stability on going from FEP to F1 and finally the aminated membranes F1NCl and F1NOH. It is interesting to note that, for the aminated membranes, the dehydration process continues well past $100^{\circ} \mathrm{C}$ indicating strong attraction between the amines and the water molecules; this correlates with the observation that a small amount of water remains in the aminated membranes even when left in a desiccator at $\mathrm{RH}=0 \%$ for $>1$ week. The hydrated membranes dehydrate in the TG apparatus with the flowing gas before commencement of the temperature program; this suggests that some water content may have been lost when mounting the hydrated membranes in the apparatus, introducing a small error. The mass loss due to loss of water content is smaller (28\%) than the measured water uptake $(38-48 \%)$; this indicates that the measurement of water uptakes using thermogravimetry is not trivial.

\section{Long-term temperature stability of F2NOH}

Scherer et al. found that the stabilities found from TG studies on membranes made from FEP grafted with styrene and sulfonated $\left(310^{\circ} \mathrm{C}\right)$ did not actually represent the true stabilities of these membranes at elevated temperatures; the desulfurisation actually occurred at lower temperatures $\left(200{ }^{\circ} \mathrm{C}\right) .{ }^{37}$ Hence, the thermal stability of $\mathbf{F 2 N O H}$ produced in this study was probed by monitoring the IEC with time when heated in water at $60^{\circ} \mathrm{C}$ and $100^{\circ} \mathrm{C}$ (only a few pieces of membrane were studied at $100^{\circ} \mathrm{C}$, as the main thermal region of interest is below $60^{\circ} \mathrm{C}$ ).

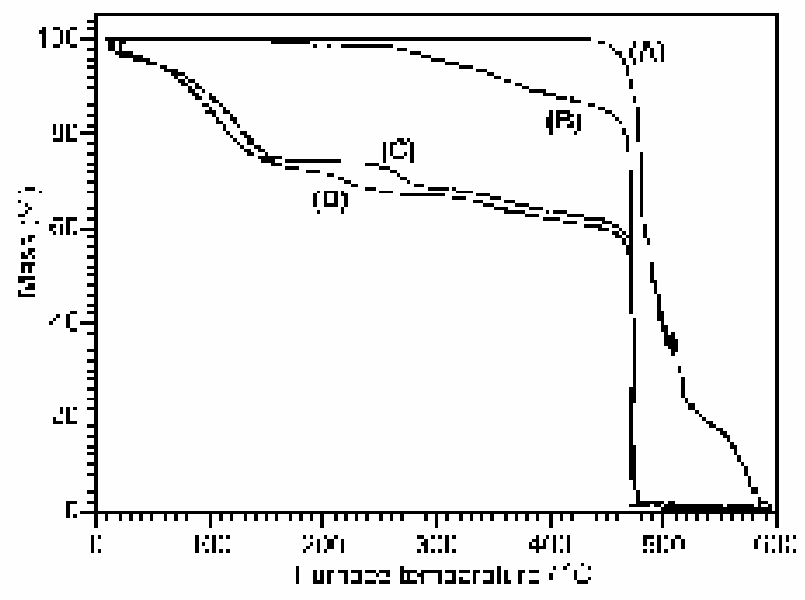

Fig. 10 Thermogravimetric analysis in oxygen $\left(60 \mathrm{~cm}^{3} \mathrm{~min}^{-1}\right)$ of (A) FEP, (B) F1, (C) F1NCI, (D) F1NOH. The small mass loss of $1.4 \%$ in trace $\mathrm{B}$ that commences at $92^{\circ} \mathrm{C}$, was due to evaporation of a small amount of trapped VBC. 


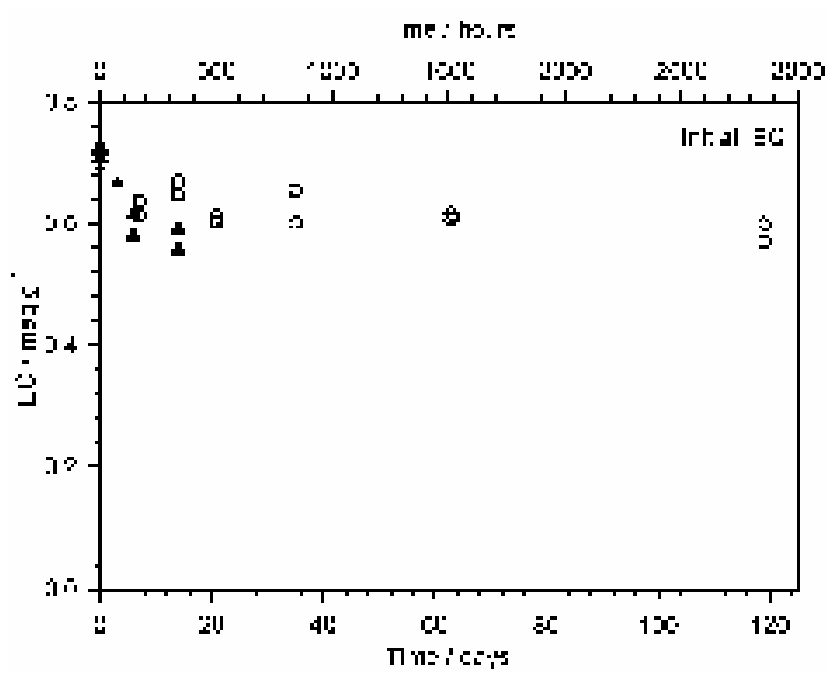

Fig. 11 The long-term stability of F2NOH as measured with the variation of IEC on heat treatment in water at $60^{\circ} \mathrm{C}(\mathbf{O})$ and $100^{\circ} \mathrm{C}(\boldsymbol{\Delta})$.

It was evident that the IEC decayed more rapidly at $100^{\circ} \mathrm{C}$ than at $60^{\circ} \mathrm{C}$ as expected (Fig. 11) for the short period of time that sample was available in the boiling water; this was expected as any displacement of the $\mathrm{NMe}_{3}$ or $\mathrm{Me}$ groups by the $\mathrm{OH}^{-}$ions would occur faster at elevated temperatures (both processes would give a reduced IEC when measured using the procedure described in this study). ${ }^{38}$ The decay of IEC at both temperatures appears to follow a curve, with a rapid initial drop in IEC, which then stabilises; more data would be required for any firm conclusions on the mechanism of decay to be established. A drop in IEC of approximately $18 \%$ of the initial IEC over a period of 119 days (2856 h) was observed with F2NOH. This indicated reasonable stability, which is expected to improve with lowering operating temperatures.

It was noted that some of the strips of membrane began to physically deteriorate into smaller pieces after 21 days (this process commenced sooner with the boiled membranes); this deterioration may have resulted either from stirring with the magnetic stirrer damaging the membranes or as an effect of the elevated temperature.

\section{Membrane conductivity}

Impedance spectroscopy measurements on the FEP-based alkaline AEMs gave similar response curves to that obtained with Nafion ${ }^{\circledR}-117$, with estimated conductivities at room temperature between $0.01-0.02 \mathrm{~S} \mathrm{~cm}^{-1}$ for both alkali-form membranes. The order of magnitude of these values is satisfactory for application of the membranes in fuel cell tests.

\section{Summary for FEP-based membranes}

In summary, FEP was successfully grafted with VBC throughout the thickness of the membrane (with $25.6 \%$ d.o.g.). Superior structural stability was retained on amination and conversion to the hydroxide anion forms compared with that found for the previous PVDF-based AEMs. The long-term thermal stability of these materials was reasonable at $60^{\circ} \mathrm{C}$ over $>2500 \mathrm{~h}$ and is expected to improve further in the target temperature range of 25 - $50^{\circ} \mathrm{C}$. Conductivities of $0.01-0.02 \mathrm{~S} \mathrm{~cm}^{-1}$ were obtained at ambient temperatures

\section{Concluding remarks}

This study shows that the alkaline AEMs produced from the radiation-grafting, with subsequent amination, of VBC onto FEP results in materials that exhibit superior structural stabilities (proved with NMR studies) compared to PVDF utilised as the base polymer. The thermal stabilities of the AEMs produced were superior at $60^{\circ} \mathrm{C}$ to that at $100^{\circ} \mathrm{C}$ with good retention of
IECs. Graft penetration was good and is expected to improve with higher grafting levels. Conductivities were high enough for application in fuel cell tests.

\section{Acknowledgments}

The authors gratefully thank Keith Lovell (Royal Military College Shrivenham, Cranfield University) for the irradiation of the FEP and PVDF films and Dr. Henryk Herman (Polymer Research Centre, UniS) for the Raman microscopic measurements. We also thank the EPSRC Solid State NMR Service at the University of Durham for the solid state NMR spectra, and Solvay Chemicals Ltd. for PVDF samples.

\section{References}

$\dagger$ The IECs were recorded with the chloride-forms to minimise displacement of the ammonium groups on immersion in aqueous potassium hydroxide

\$ Only batches of two could be measured for the long-term thermal stability tests on F2NOH membranes to economise the use of material.

$\S$ The maximum theoretical IECs are calculated from the mass gain on grafting and assuming $100 \%$ amination and no other side reactions on grafting/amination. Values slightly lower than these theoretical values are always expected as some water remains after vigorous drying (confirmed with thermogravimetry); however, the values obtained with the PVDF-based materials are significantly lower than expected.

1 S. Dunn, Int. J. Hydrogen Energy, 2002, 27, 235; C. Stone, A. E. Morrison, Solid State Ionics, 2002, Advance article.

2 EyeforFuelCells conference on Fuel Cells for Portable Applications, Hilton Back Bay, Boston, U.S.A., September $5^{\text {th }}-6^{\text {th }} 2002$; X. Ren, P. Zelenay, S. Thomas, J. Davey, S. Gottesfeld, J. Power Sources, 2000, 86, 111; J. W. Raadschelders, T. Jansen, J. Power Sources, 2001, 96, 160. D. Cohen, New Scientist, $19^{\text {th }}$ October 2002, 176, issue 2365, page 40; Fuel Cell Seminar 2002, Palm Springs Convention Center, Palm Springs, U.S.A., November 2002.

3 J. P. Meyers, H. L. Maynard, J. Power Sources, 2002, 109, 76; D. Chu, R. Jiang, Solid State Ionics, 2002, 148, 591; C. K. Dyer, J. Power Sources, 2002, 106, 31; C. Hebling, A. Heinzel, Fuel Cell Bull., July 2002, 8; H. Chang, J. R. Kim, J. H. Cho, H. K. Kim, K. H. Choi, Solid State Ionics, 2002, 148, 601.

4 P. Dimitrova, K. A. Friedrich, B. Vogt, U. Stimming, J. Electroanal. Chem., 2002, 532, 75.; V. M. Barragán, A. Heinzel, J. Power Sources, 2002, 104, 66; Z. Qi, A. Kaufman, J. Power Sources, 2002, 110, 177; J. Cruickshank, K. Scott and W Taama, J. Power Sources, 1997, 65, 159; B. Gurau, E. S. Smotkin, J. Power Sources, 2002, 112, 339 .

5 (a) G. F. McLean, T. Niet, S. Prince-Richard, N. Djilali, Int. J. Hydrogen Energy, 2002, 27, 507.; (b) F. Jaouen, WO Patent 02/35633/A1, 2002; (c) R. R. Adzic, M. C. Aramtor, A. V. Tripkovic, Electrochim. Acta, 1984, 29, 907; (d) J. Taraszewska, G. Roslonek, J. Electroanal. Chem., 1994, 364, 209.

6 (a) J. Divisek, WO Patent 01/61776/A1, 2001; (b) W. Yao, T. Tsai, Y.-M. Chang, M. Chen, US Patent 6,183,914, 2001; (c) E. Agel, J. Bouet, J.-F. Fauvarque, H. Yassir, Ann. Chim. Sci. Mater., 2001, 26, 59; (d) J.-F. Fauvarque, US Patent 5,569,559, 1986. (e) E. Agel, J. Bouet, J. F. Fauvarque, J. Power Sources, 2001, 101, 267; (f) B. Xing, O. Savadogo, Electrochem. Commun., 2000, 2, 697.

7 T. Sata, M. Tsujimoto, T. Yamaguchi, K. Matsusaki, J. Membr. Sci., 1996, 112, 161.

8 Q. Guo, P. N. Pintauro, H. Tang, S. O'Connor, J. Membr. Sci., 1999, 154, 175.

9 J. A. Kerres, J. Membr. Sci., 2001, 185, 3; J. Yu, B. Yi, D. Xing, F. Liu, Z. Shao, Y. Fu, J. Power Sources, 2002, Advance article.

10 D. E. Curtain, "High volume, low cost manufacturing process for Nafion ${ }^{\circledR}$ membranes", p834 in the Abstracts for Fuel Cell Seminar 2002, Palm Springs Convention Center, Palm Springs, U.S.A., November $18^{\text {th }}-21^{\text {st }} 2002$.

11 (a) K. V. Lovell, J. A. Horsfall, Eur. Polym. J., 2002, 38, 1671; (b) J. A. Horsfall, K. V. Lovell, Fuel Cells, 2002, 1, 186; (c) J. A. Horsfall, K. V. Lovell, Polym. Adv. Tech., 2002, 13, 381.

12 C. Chuy, V. I. Basura, E. Simon, S. Holdcroft, J. Horsfall, K. V. Lovell, J. Electrochem. Soc., 2000, 147, 4453.; S. Hietala, S. L. Maunu, F. Sundholm, T. Lehtinen, G. Sundholm, J. Polym. Sci.: Part B: Polym. Phys., 1999, 37, 2893; S. D. Flint, R. C. T. Slade, Solid State Ionics, 1997, 97, 299. 
13 (a) H.-P. Brack, H. G. Bührer, L. Bonorand, G. G. Scherer, J. Mater. Chem., 2000, 10, 1795; B. (b) Gupta, F. N. Büchi, M. Staub, D. Grman, G. G. Scherer, J. Polym. Sci. Part A: Polym. Chem., 1996, 34, 1873; (c) F. N. Büchi, B. Gupta, O. Haas, G. G. Scherer, Electrochim. Acta, 1995, 40, 345; (d) B. Gupta, F. N. Büchi, G. G. Scherer, J. Polym. Sci. Part A: Polym. Chem., 1994, 32, 1931.

14 K. Scott, W. M. Taama, P. Argyropoulos, J. Membr. Sci., 2000, 171, 119.

15 G. Hübner, E. Roduner, J. Mater. Chem., 1999, 9, 409.

16 M. Camps, M. Chatzopoulos, J.-P. Monthéard, J. Macromol. Sci. Macromol. Chem. Phys., 1982, C22, 343; J.-P. Monthéard, C. Jegat, M. Camps, J. Macromol. Sci. Macromol. Chem. Phys., 1999, C39, 135; VBC product information brochure from the Dow Chemical Company.

17 (a) B. L. Svarfar, K. B. Elkman, M. J. Sundell, J. H. Näsman, Polym. Adv. Tech., 1996, 7, 839; (b) J. Sandeaux, R. Sandeaux, G. Pourcelly, J. Molénat, J. Membr. Sci., 1993, 84, 213; (c) W. Lee, K. Saito, S. Furusaki, T. Sugo, K. Makuuchi, J. Membr. Sci., 1993, 81, 295; (d) T. Cohen, P. Dagard, J. Molénat, B. Brun, C. Gavach, J. Electroanal. Chem., 1986, 210, 329.

18 T. N. Danks, R. C. T. Slade, J. R. Varcoe, J. Mater. Chem., 2002, 12, 3371 .

19 G. J. Ross, J. F. Watts, M. P. Hill, P. Morrissey, Polymer, 2000, 41, 1685; G. J. Ross, J. F. Watts, M. P. Hill, P. Morrissey, Polymer, 2001, 42, 403; P. Hinksman, D. H. Isaac, P. Morrissey, Polym. Degrad. Stab., 2000, 68, 299; G.Moggi, P. Bonardelli, G. Chiodini, S. Conti, A. Fontana, J. Fluorine Chem., 1985, 29, 167.

20 M. Lobayashi, K. Tashiro, H. Tadokoro, Macromolecules, 1975, 8, 158

21 B. Mattsson, H. Ericson, L. M. Torell, F. Sundholm, Electrochim. Acta, 2000, 45, 1405; U. Hoffmann, F. Pfeifer, S. Okretic, N. Völkl, M. Zahedi, H. W. Siesler, Appl. Spectr., 1993, 47, 1531; B. Mattsson, H. Ericson, L. M. Torell, F. Sundholm, J. Polym. Sci.: Part A: Polym. Chem., 1999, 37, 3317; S. Hietala, M. Paronen, S. Holmberg, J. Näsman, J. Juhanoja, M. Karjalainen, R. Serimaa, M. Toivola, T. Lehtinen, K. Parovuori, G. Sundholm, H. Ericson, B. Mattsson, L. Torell, F. Sundholm, J. Polym. Sci.: Part A: Polym. Chem., 1999, 37, 1740.

22 B. Jasse, R. S. Chao, J. L. Koenig, J. Polym. Sci. : Polym. Phys. Ed., 1978, 16, 2157.

23 Z. G. Yan, Y. L. Deng, D. Zhang, C. Q. Yang, J. Polym. Sci.: Part A: Polym. Chem., 2001, 39, 1031.

24 P. Holstein, G. A. Monti, R. K. Harris, Phys. Chem. Chem. Phys., 1999, 1, 3549; W. Su, D.-L. M. Tzou, Polymer, 2000, 41, 7289; S. Ando, R. K. Harris, S. A. Reinsberg, Magn. Reson. Chem., 2002, 40, 97.

25 P. Holstein, U. Scheler, R. K. Harris, Magn. Reson. Chem., 1997, 35, 647.

26 S. Hietala, S. L. Maunu, F. Sundholm, Macromolecules, 1999, 32, 788.

27 S. Mohanraj, W. T. Ford, Macromolecules, 1985, 18, 351.

28 A. Oshima, S. Ikeda, E. Katoh, Y. Tabata, Rad. Phys. Chem., 2001, 62, 39.

29 A. Gruger, A. Régis, T. Schmatko, P. Colomban, Vibr. Spectrosc., 2001, 26, 215.

30 M. M. Nasef, H. Saidi, H. M. Nor, J. Appl. Polym. Sci., 2000, 76, 220; M. V. M. V. Roully, E. R. Kötz, O. Haas, G. G. Scherer, A. Chapiró, J. Membr. Sci., 1993, 81, 89.

31 K. Lunkwitz, U. Lappan, D. Lehmann, Rad. Phys. Chem., 2000, 57, 373.

32 F. Cardona, G. A. George, D. J. T. Hill, F. Rasoul, J. Maeji, Macromolecules, 2002, 35, 355; F. Cardona, G. A. George, D. J. T Hill, S. Perera, J. Polym. Sci.: Part A: Polym. Chem., 2002, 40, 3191.

33 J. S. Forsythe, D. J. T. Hill, S. Mohajerani, A. K. Whittaker, Rad. Phys. Chem., 2001, 60, 439.

34 B. Gupta, O. Haas, G. G. Scherer, J. Appl. Polym. Sci., 1994, 54, 469. B. Gupta, G. G. Scherer, Angew. Makromol. Chem.,1993, 210 , 151.

35 B. Gupta, G. G. Scherer, J. G. Highfield, Angew. Makromol. Chem., 1998, 256, 81.

36 M. M. Nasef, H. Saidi, Polym. Degrad. Stab., 2000, 70, 497.

37 B. Gupta, G. G. Scherer, J. Appl. Polym. Sci., 1993, 50, 2129.

38 V. N. Neagu, I. Bunia, I. Plesca, Polym. Degrad. Stab., 2000, 70, 463; A. A. Zagorodni, D. L. Kotova, V. F. Selemenev, React. Funct. Polym., 2002, Advance Article. 